\title{
Deposition of pressurised aerosols in the human respiratory tract
}

\author{
STEPHEN P NEWMAN, DEMETRI PAVIA, FOLKE MORÉN, NOIRÍN F SHEAHAN, \\ AND STEWART W CLARKE
}

From the Departments of Medical Physics and Thoracic Medicine, The Royal Free Hospital, London, and $A B$ Draco, Lund, Sweden

ABSTRACT Although the use of pressurised aerosol inhalers is widespread, little is known abouto the actual deposition of the aerosol in the respiratory tract, since this has previously been diffi- - cult to measure. We have incorporated Teflon particles (mean diameter $2 \mu \mathrm{m}$ ) with aerodynamic properties similar to those of bronchodilator drug crystals into pressurised aerosol canisters. Controlled inhalations by eight patients with obstructive airways disease showed that on average $8.8 \%$ of the dose was deposited in the lungs $(3.0 \%$ in the alveoli and $5.8 \%$ on the conducting $\overrightarrow{0}$ airways) and $80 \%$ in the mouth. These figures are in good agreement with previous indirect estimates of deposition based on metabolic studies. The remainder of the dose was either expired $(1.0 \%)$ or deposited in the aerosol actuator $(9.8 \%)$. This method should have wide application罗 for measurement of deposition patterns under various conditions and for assessment of thera- $-\frac{\widehat{O}}{\mathrm{a}}$ peutic effects.

Since the identification of specific $\beta_{2}$ receptors in the human respiratory tract, ${ }^{1}$ selective sympathomimetic bronchodilator aerosols have been in common use for the treatment of asthma. Pressurised canisters are a portable and convenient means of administering these and other aerosols. In spite of this widespread use, relatively little is known about the deposition of pressurised aerosols in the respiratory tract. Because of the delivery mechanism of pressurised aerosols, involving large propellant droplets travelling initially at very high velocities, ${ }^{2}$ previously published measurements of aerosol deposition during quiet breathing ${ }^{34}$ are inapplicable. Attempts to estimate deposition of pressurised aerosols have almost always been indirect because of difficulties in labelling the aerosol particles with a suitable radioisotope. Studies based upon the plasma levels of bronchodilators and their metabolites after oral and inhaled doses have suggested that the majority $(80 \%)$ of the bronchodilator dose is deposited in the mouth and subsequently swallowed and that only $10 \%$ reaches the lung directly. ${ }^{5}{ }^{5}$ As these figures are only approximate and give no indication of the deposition pattern within the lung, the per-

Address for reprint requests: Dr SP Newman, Department of Medica 1 Physics, The Royal Free Hospital, Pond Street, London NW3 2QG. centages of the dose deposited on the conducting 3 airways and in the alveoli are unknown. In this paper we present the first direct measurement of the deposition of pressurised inhalation aerosols, using an objective in vivo radioactive technique.

\section{Methods}

In order to study the deposition of pressurised aerosols, we have incorporated Teflon particles (density $2 \cdot 1 \mathrm{gm} \mathrm{cm}^{-3}$ ), generated by the spinning 음 disc technique, ${ }^{7}$ into metered-dose inhalers. A fine $\rightarrow$ suspension of fluorocarbon resin (Teflon 120, Dupont) in a mixture of $40 \%$ ethanol and ${ }^{99 m}$ tech- $N$ netium (Tc) was delivered to the centre of the rapidly rotating disc. The particles generated 0 (mean diameter $2 \mu \mathrm{m}$, standard deviation $0.4 \mu \mathrm{m}$ ) $\omega$ were allowed to settle onto the base of a large? airtight tank inside which the generator was situ- $\bullet$ ated. After collection, the ${ }^{99 m}$ Tc was firmly sealed $\mathbb{D}^{\circ}$ within the particles by heating at $240^{\circ} \mathrm{C}$ for five $\stackrel{+}{+}$ minutes.

The pressurised canisters and valves used in this $\frac{\overrightarrow{0}}{\vec{D}}$ study were those available commercially for the $\stackrel{\odot}{\mathbb{D}}$ delivery of terbutaline sulphate (Bricanyl, Astra $\unrhd$ Pharmaceuticals). Eight $\mathrm{mg}$ of the Teflon particles were placed inside an open canister, and $2 \mathrm{ml}$ of $\delta$ 
fluorocarbon propellants (freons 11,12 , and 114 mixed in the ratio $1: 2: 1)$ containing sorbitan trioleate surfactant $(14 \mathrm{mg} / \mathrm{ml})$ were added at $-60^{\circ} \mathrm{C}$. A valve mechanism was mounted on top of the canister, which was immediately sealed with a hand-crimper. An ultrasonic vibrator was then used to disperse the Teflon into a suspension of discrete particles within the canister. Each metered dose released $25 \mu \mathrm{l}$ of propellant, containing $100 \mu \mathrm{g}$ of Teflon particles. Examination of doses fired directly onto microscope slides showed that the particles were unaltered in size by their immersion in propellants and that less than $2 \%$ of the particles agglomerated to form multiplets. The aerodynamic mass median diameter of the Teflon particles $(3.2 \mu \mathrm{m})$ was similar to that determined for terbutaline sulphate drug crystals.

For inhalation by patients, the aercsol canister was mounted in a specially designed apparatus which enabled flow rate and inhalation volume to be measured (fig 1). The aerosol actuator was connected in series with a pneumotachygraph and the differential pressure signal sampled at $10 \mathrm{~ms}$ intervals by a Varian V-77 200 computer. The flow rate was integrated to give inhaled volume, and the aerosol canister was fired during the course of inhalation by a solenoid mounted on top of the aerosol actuator. The lung volume at which the canister was actuated could be preset by means of a computer program written in Fortran. At the end of inhalation, the computer produced a printout listing inhaled volume, flow rate, the lung volume at which the canister was fired, and breath-holding pause at total lung capacity.

Eight patients with obstructive airways disease (six asthmatics, two chronic bronchitics, mean
FEV $_{1} 49 \%$ predicted) inhaled six puffs of the aerosol in a manner similar to that recommended by the manufacturers of pressurised bronchodilators. The dose was fired in the early stages of a rapid inhalation from residual volume to total lung capacity, and inhalation was followed by four seconds of breath-holding to allow time for particles to deposit on the airways by sedimentation under gravity. After each breath-holding period, the subject exhaled through a Martindale filter and then rinsed the mouth several times with water. The percentages of the administered activity in expired air, actuator, and mouthwash were measured by comparing counts in these items against the count obtained when several metered doses were fired into a beaker of water. ${ }^{8}$

Activity not accounted for in exhaled air, actuator, and mouthwash was measured immediately after inhalation using a shadowshield whole body counter consisting of two (NaI(T1) crystals mounted above and below a moving couch. ${ }^{9}$ The field of view of each detector was restricted to a narrow slit by means of steel collimators placed $1 \mathrm{~cm}$ apart. The subject lay supine on the couch, which travelled at a speed of $0.2 \mathrm{~cm}$ $\mathrm{s}^{-1}$ through the field of view of the detectors, and the profile of activity in head and trunk was displayed graphically on a chart recorder. ${ }^{10}$ Three distinct regions were identified on the profile scans, corresponding to activity in mouth, lung, and stomach. The area under each region of the profile scan curve was measured and corrected for the different effective thickness of head, chest, and abdomen to give the percentages of the dose located at each site. The percentage of the dose initially deposited in the mouth was calculated as

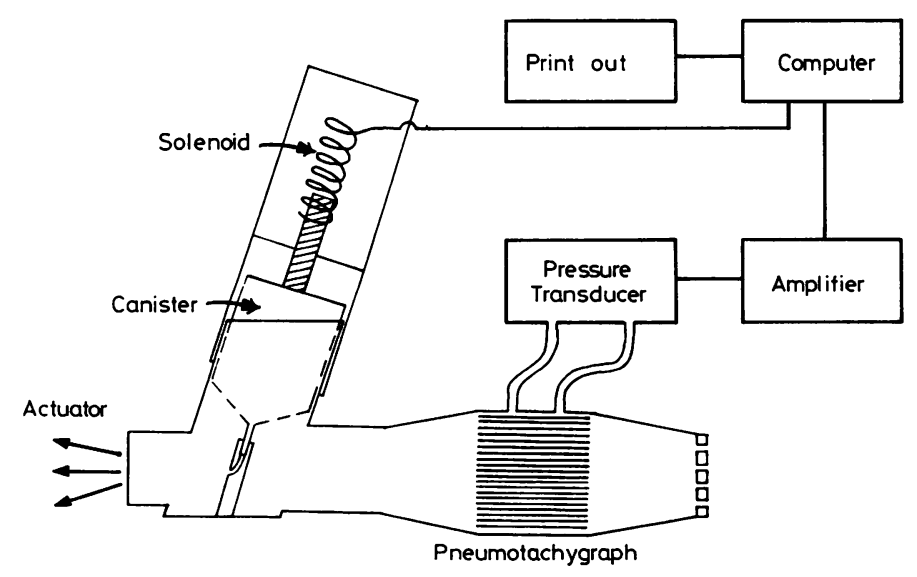

Fig 1 Diagrammatic representation of the apparatus used to administer radiolabelled Teflon particles from pressurised canisters. 
the sum of percentages found in the mouth, mouthwash, and stomach.

A dual detector probe system, ${ }^{11}$ collimated so as to include most of both lungs but to exclude the stomach, was used to count the lung deposit shortly after inhalation and then $24 \mathrm{~h}$ later. The fraction of the initial lung burden present at $24 \mathrm{~h}$, corrected for radioactive decay, was used as a measure of alveolar deposition of inhaled Teflon particles. ${ }^{4} 12$

Each patient gave informed consent in writing, and the studies were approved by the Ethical Practices Committee of the Hospital.

\section{Results}

The mean percentages of the dose deposited at various sites are summarised in fig 2 , and a typical gamma camera picture of the head, chest, and stomach of one patient shortly after inhalation is shown in fig 3 . In eight patients, the mean percentage of the dose deposited in the lungs was $8.8 \%$ (SD $3.4 \%$, range $4 \cdot 7-14.8 \%$ ) of which $3.0 \pm$ $3.1 \%$ (mean \pm SD) was deposited in the alveoli and $5 \cdot 8 \pm 2.6 \%$ on the conducting airways. The percentage of the dose initially deposited in the mouth was $80 \cdot 4 \pm 6 \cdot 0 \%$ (range $70 \cdot 2-89 \cdot 1 \%$ ). The remainder of the dose was deposited in the aerosol actuator (mean $9.8 \%$ of dose) or was recovered from the expired air (mean $1.0 \%$ of dose). The aerosol canister was fired at $21 \pm 4 \%$ vital capacity during the course of a rapid inhalation (average flow rate $67 \cdot 2 \pm 20 \cdot 31 \mathrm{~min}^{-1}$, maximum flow rate $127 \cdot 2 \pm 43.61 \mathrm{~min}^{-1}$ ). The breath-holding pause after inhalation was $3 \cdot 9 \pm 0 \cdot 2$ seconds.

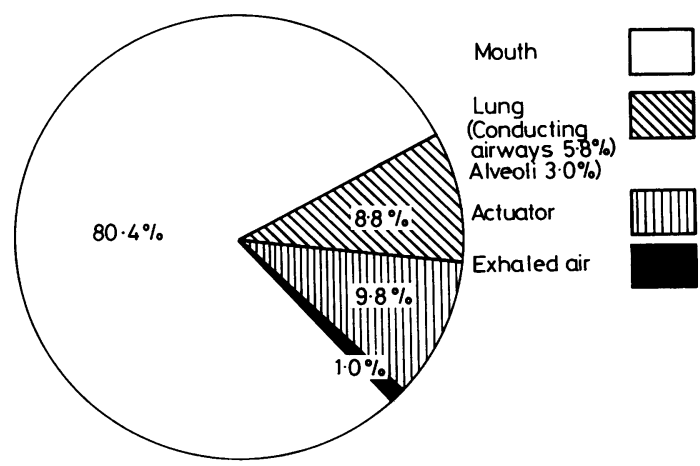

Fig 2 Fractional deposition of ${ }^{9{ }^{m}} T$ T-labelled Teflon particles, administered from pressurised canisters.

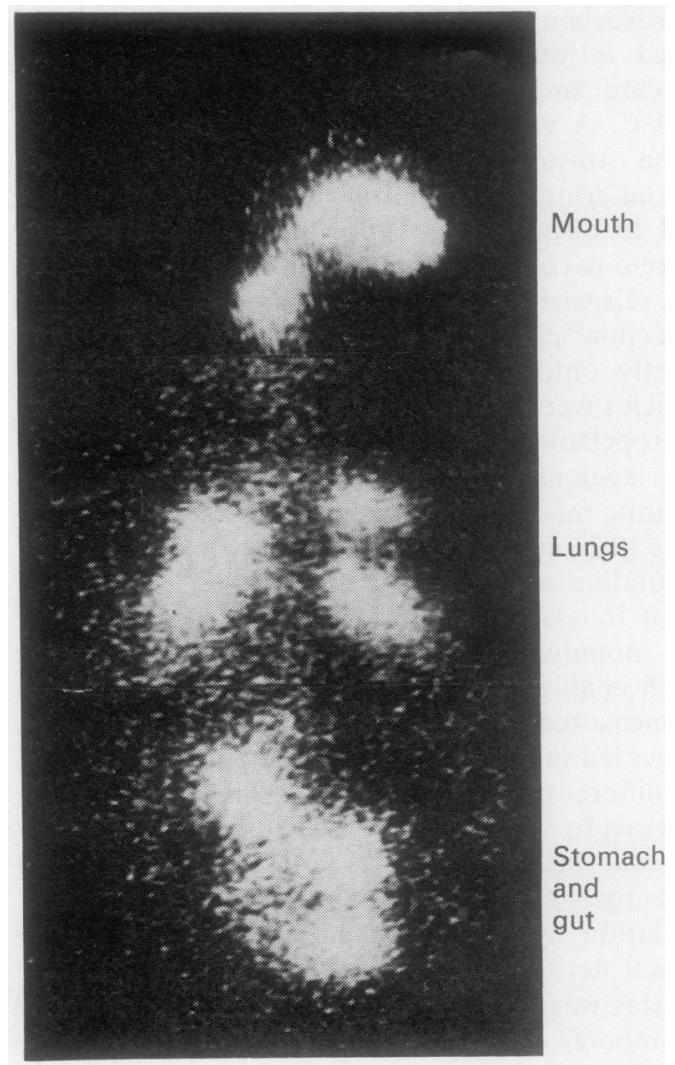

Fig 3 Gamma camera picture of mouth, lungs, and abdomen of one asthmatic subject, showing typical radioaerosol distribution after inhalation of ${ }^{99 m} \mathrm{Tc}$ labelled Teflon particles from pressurised canisters.

\section{Discussion}

These results confirm the findings of earlier indirect studies ${ }^{56}$ and indicate that on average less than $10 \%$ of the dose from a pressurised inhaler reaches the lungs when the inhaler is used according to manufacturers' instructions. This would correspond to less than $50 \mu \mathrm{g}$ of a $500 \mu \mathrm{g}$ dose of terbutaline sulphate. Although almost $80 \%$ of the dose is deposited in the mouth and would normally be swallowed, it has been shown that the quantities of drug involved are too small to cause significant bronchodilatation as an oral dose, ${ }^{13}$ and that bronchodilator aerosols must deposit in the lung if they are to be effective. Bearing in mind the large surface areas of both alveoli and conducting airways, it is remarkable that such small amounts of drug can give effective bronchodilatation. 
Approximately $40 \%$ of the lung deposit was located initially in the alveoli, indicating that bronchodilator drug particles are deposited throughout the respiratory tract. There is at present some confusion as to the whereabouts of the receptor sites for inhaled bronchodilators, although the bulk of the evidence suggests that these receptors are probably located in the smaller conducting airways, less than $2 \mathrm{~mm}$ in diameter. ${ }^{14}$ Aerosol deposition depends critically upon the volume and flow rate of inhalation ${ }^{15}$ and upon the subsequent breath holding pause ${ }^{16}$ so that the amount of aerosol reaching each lung region could be modified by varying the mode of inhalation. We hope, therefore, that a systematic study of pressurised aerosol deposition under various carefully controlled inhalation conditions will enable the maximum amount of aerosol to be directed towards its required site of action. Pressurised aerosol bronchodilators have been under suspicion as a contributory factor to the rise in asthma deaths in the late 1960s, ${ }^{17}$ and any improvement in the precision of aerosol therapy may be an important advance. The low radiation doses resulting from ${ }^{9{ }^{9 m}} \mathrm{Tc}$ permit a series of studies to be safely performed on a single patient. Six puffs of aerosol deposit an initial lung burden of $10 \mu \mathrm{Ci}{ }^{99^{\mathrm{m}}} \mathrm{Tc}$, and the radiation dose to the lung resulting from this amount of activity labelled to insoluble particles is believed not to exceed 12 mrad. ${ }^{18}$

We would like to thank $\mathrm{Mr} \mathrm{A}$ Lister, Interdepartmental Workshop, Royal Free Hospital, for constructing the spinning disc generator, $\mathrm{Mr}$ W Welch, Department of Medical Physics, for writing computer programs necessary for the operation of the inhalation apparatus, and Astra Pharmaceuticals for financial support.

\section{References}

1 Lands AM, Arnold A, McAuliff JP, Luduena FP, Brown TG. Differentiation of receptor systems activated by sympathomimetic amines. Nature 1967; 214:597-8.

2 Rance RW. Studies of the factors controlling the action of hair sprays. III. The influence of particle velocity and diameter on the capture of particles by arrays of hair fibres. J Soc Cosmet Chem 1974; 25:545-61.

3 Foord N, Black A, Walsh M. Pulmonary deposition of inhaled particles with diameters in the range $2 \cdot 5-7 \cdot 5 \mu$. In: Walton $\mathrm{WH}$, ed. Inhaled particles IV. Oxford: Pergamon Press, 1977; 1: 137-48.

4 Lippmann M, Albert RE. The effect of particle size on the regional deposition of inhaled aerosols in the human respiratory tract. Am Ind Hyg Assoc J 1969; 30:257-75.

5 Davies DS. Pharmacokinetics of inhaled substances. Postgrad Med J 1975; 51: Supplement 7, 69-75.

6 Walker SR, Evans ME, Richards AJ, Paterson JW. The clinical pharmacology of oral and inhaled salbutamol. Clin Pharmacol Ther 1972; 13: 861-7.

7 Camner P, Philipson K, Linnman L. A simple method for nuclidic tagging of monodisperse fluorocarbon resin particles. Int J Appl Radiat Isotopes 1971; 22:731-4.

8 British Pharmaceutical Codex. Aerosol inhalations. London: pharmaceutical press 1977; 643-8.

9 Warner GT, Oliver R. A whole body counter for clinical measurements using the "shadow shield" technique. Phys Med Biol 1966; 11:83-94.

10 Tothill P, Galt JM. Quantitative profile scanning for the measurement of organ radioactivity. Phys Med Biol 1971; 16:625-34.

11 Pavia D, Thomson ML. The fractional deposition of inhaled 2 and $5 \mu \mathrm{m}$ particles in the alveolar and tracheobronchial regions of the healthy human lung. Ann Occup Hyg 1976; 19:109-14.

12 Camner P, Philipson K. Human alveolar deposition of $4 \mu \mathrm{m}$ Teflon particles. Arch Environ Health 1978; 33:181-5.

13 Ruffin RE, Montgomery JM, Newhouse MT. Site of beta-adrenergic receptors in the respiratory tract. Chest 1978; 74:256-60.

14 Hensley MJ, O'Cain CF, McFadden ER, Ingram RH. Distribution of bronchodilatation in normal subjects: beta agonist versus atropine. J Appl Physiol 1978; 45:778-82.

15 Goldberg IS, Lourenco RV. Deposition of aerosols in pulmonary disease. Arch Intern Med 1973; 131:88-91.

16 Palmes ED, Altshuler B, Nelson N. Deposition of aerosols in the human respiratory tract during breath holding. In: Davies $\mathrm{CN}$, ed. Inhaled particles and vapours II. Oxford: Pergamon Press 1967; 339-48.

17 Speizer FE, Doll R, Heaf P. Observations on a recent increase in mortality from asthma. $\mathrm{Br} \mathrm{Med}$ J 1968; 1:335-9.

18 Pavia D. Studies on the mucociliary clearance from the human lung with special reference to the effects of tobacco smoking. London University PhD Thesis, 1974. 